\title{
Antioxidant Properties of Ewe versus Cow Yogurt and Effect of Its Consumption on Cortisol Levels of Adults (Borderline-high Cholesterol Levels)
}

\author{
Natalia García-Gonzalez ${ }^{1,2}$, Carmen Asensio-Vegas $^{2}$, Daniel Rico $^{1}$, Begoña Olmedilla-Alonso ${ }^{3}$, \\ Esther Nova ${ }^{3}$, Elena Peñas ${ }^{3}$, Ana B. Martin-Diana ${ }^{1, *}$
${ }^{1}$ Agro Technological Institute, Deputy Directorate of Research and Technology, Area of Innovation and Process Optimisation, Ctra. de Burgos Km. 119, 47071 Valladolid, Spain
${ }^{2}$ Agro Technological Institute, Deputy Directorate of Research and Technology, Dairy Technological Station, Avda. Viñalta s/n, 34071 Palencia, Spain
${ }^{3}$ Department of Metabolism and Nutrition, Institute of Food Science, Technology and Nutrition (ICTAN-CSIC), C/ Jose Antonio Novais, 10, 28040 Madrid, Spain C/ Jose Antonio Novais, 10, 28040 Madrid, Spain
*Corresponding author: mardiaan@itacyl.es \\ ${ }^{4}$ Department of Characterization, Quality and Safetyn, Institute of Food Science, Technology and Nutrition (ICTAN-CSIC),
}

\begin{abstract}
Antioxidant in vitro markers were used to evaluate the total antioxidant activity of ewe (whole and semi-skimmed) and cow's set yogurts. Results showed that cow set yogurt had significantly $(p \leq 0.05)$ total higher antioxidant activity than ewe set yogurt and peptidic fraction had significant higher contribution to the total antioxidant activity compared to lipidic and/or phenolic fraction. However, when lipidic fraction was evaluated, ewe yogurt (whole and skimmed) had higher antioxidant activity than cow probably associated to the high levels of conjugated linoleic acid (CLA) in ewe milk. Although significant differences win cortisol levels were observed in certain groups of population studied (normal risk woman) regarding consume ewe yogurt, it is not possible to conclude a significant lowering effect of ewe yogurt on cortisol levels in general population.
\end{abstract}

Keywords: antioxidant activity, peptides, ewe, cow, cortisol, yogurt

Cite This Article: Natalia García-Gonzalez, Carmen Asensio-Vegas, Daniel Rico, Begoña Olmedilla-Alonso, Esther Nova, Elena Peñas, and Ana B. Martin-Diana, "Antioxidant Properties of Ewe's versus Cow's Yogurt and Effect of Its Consumption on Cortisol Levels of Adults (Borderline-high Cholesterol Levels)." Journal of Food and Nutrition Research, vol. 6, no. 6 (2018): 346-355. doi: 10.12691/jfnr-6-6-1.

\section{Introduction}

The cell oxidative damage caused by reactive oxygen species and free radicals is one of the most important factors associated with chronic such as overweight and obesity conditions that are closely related with an increased risk of several degenerative diseases.

The rising of the prevalence of these diseases has led to an increased number of studies evaluating the relationship between food and health. Dairy products can be considered as a functional food or superfood since they provide a wide range of macro and micronutrients that are biologically active and with a possible effect on human health beyond nutritive aspects [1].

Dairy products are one of the most interesting foods with regard to their potential antioxidant activity, due to their important diversity of antioxidant molecules such as milk caseins, whey proteins and low molecular weight peptides $[2,3,4]$.Furthermore, milk and milk-derived products contain a wide range of antioxidant molecule traces, such as low molecular weight thiols $[5,6]$ tocopherol, and carotenoids [7,8], among others. In addition, approximately one third of the fat in whole milk is monounsaturated and small amounts of essential fatty acids can be provided from milk intake. Milk is one of the major sources of conjugated linoleic acid (CLA) in the diet, although it is a minor component of milk fat [9]. Many possible health benefits are associated with the consumption of CLA by humans has been associated with many possible health benefits including antioxidant activity, immune response and lipid metabolism modulation [10]. One of the major sources of this group of compounds are dairy products such as milk, cream, yogurt, cheese and butter [11].

Amongst dairy products, yogurt is a fermented food with an important quantity of fatty acids, vitamins, highquality proteins and minerals. The fermentative processes by lactic acid bacteria (LAB) increase its value making more digestible its nutrients, mainly milk proteins, and providing bioactive peptides $[3,4]$. LAB and other strains used in fermentation have probiotic activities that improve the properties of the yogurt. Moreover, protein hydrolysis by LAB proteolytic enzymes produces free amino acids and oligopeptides increasing its nutritional value. 
Antioxidant compounds in yogurt could be differentiated by its nature between lipophilic (conjugated linoleic acid, -tocopherol, b-carotene, etc.) and hydrophilic (proteins, peptides, vitamins and minerals) [12], being different their concentration and their respective contribution as natural scavenging molecules is different.

Cortisol is a human hormone that acts as multidirectional since it is involved in many physiological processes affects the metabolism of proteins, carbohydrates and fats and also participates in the regulation of water and electrolyte balance, blood pressure, body temperature, mineralization of the bones and the immune response $[13,14,15]$.

The nutrient in the diet and the physical activity have an important impact on the endocrine system and, in particular, in cortisol levels. Several authors have reported the effect of different compounds on the regulation of cortisol. [16] demonstrated than there is an influence of ascorbic acid on cortisol levels and then the ingest of 3000 $\mathrm{mg}$ of vitamin $\mathrm{C}$ per day leads to a faster cortisol recovery after response to acute psychological stress, although did not decrease overall concentration of this hormone. Other compound that has been described as cortisol regulator is the $\gamma$-aminobutyric acid (GABA). GABA reduces the secretion of corticoliberin, which triggers a series of hormonal changes, leading to secretion of cortisol by the adrenal cortex [17]. In addition, other natural sources such as fermented milk products have been appointed ascortisol levels modulators $[18,19]$. For this reason, the purpose of this study was to evaluate the antioxidant properties of ewe yogurts compared to cow's yogurt (control) and their impact on cortisol levels.

\section{Material and Methods}

\subsection{Raw Material}

Ewe yogurts were prepared using fresh raw milk from Spanish Churra sp. sheep breed kindly provided by the School of Viñalta (Palencia, Spain). Milk was obtained from animals that were handled in accordance with Directive 2010/63/EU for the protection of animals used for scientific purposes. The commercial yogurt culture YF-L903 (Chr. Hansen, Madrid, Spain) which contains a mixture of $S$. thermophilus and L. bulgaricus was used for direct batch inoculation in ewe's milk. The control yogurts were obtained from a commercial brand and were prepared from Holstein cow's milk. Twelve manufacturing batches were carried out.

\subsection{Yogurts Elaboration}

Twelve manufacturing batches for the two ewe types of yogurts were prepared from January to June 2015: (1) ewe's semi-skimmed-milk yogurt (ES) (2.8\% fat), (2) ewe's whole-milk yogurt (EW) (5.8\% fat). The ewe's milk was processed in Estación Tecnológica de la Leche (ETL, Palencia), within $2 \mathrm{~h}$ after reception. Milk base was strained using a cloth filter and divided into two batches of 30 L. Ewe's milk was standardized and pasteurized at $80^{\circ} \mathrm{C}$ for $30 \mathrm{~min}$. Afterwards, the milk was cooled to $42-43^{\circ} \mathrm{C}$ and inoculated with starters. The lyophilized cultures were prepared individually and used according to manufacturer instructions. Both mixtures were transferred to tightly closed plastic cups $(125 \mathrm{~mL})$, closed and incubated (Portinox ARGBT 700-1P, Sevilla, Spain) at $42^{\circ} \mathrm{C}$ until $\mathrm{pH}$ value reached 4.6. Yogurts were stored at $4^{\circ} \mathrm{C}$ for antioxidant analysis and sent to the Institute of Food Science, Technology and Nutrition (ICTAN) (Madrid) where they were used in a crossover study [20] with cow commercial yogurt. All the yogurts prepared were evaluated from antioxidant perspective. Four different fractions were separated in all the yogurts: total fraction (F1), peptidic (F2), phenolic (F3) and lipophilic (F4) fraction, in order to evaluate the contribution of each fraction in the total antioxidant activity. Folin-Ciocalteu (FC) for total phenol (TPs) assay, (TP), DPPH (1,1diphenyl-2-picrylhydrazyl) radical scavenging activity Radical (DPPH), Trolox Equivalent Antioxidant Capacity (TEAC), Oxygen Radical Absorbance Capacity (ORAC) and relative antioxidant capacity (RACI) were evaluated. The F2 was further characterized using high performance liquid chromatography (HPLC), sodium Dodecyl SulfatePolyacrylamide Gel Electroforesis (SDS-PAGE) and determination of proteinhydrolysis degree (OPA).

\subsection{Clinical Assay}

A randomized crossover nutritional intervention study was carried out from January 2015 to July 2015. Every part of the intervention had a 5 week (wk) duration with a daily consumption of 2 set yogurts of $125 \mathrm{~g}$ of any of the CW, ES and EW yogurts. During the three phases of the study, the volunteers consumed in random order the three types of yogurts; whole ewe yogurt (5.8 \% milk fat), semiskimmed ewe yogurt $(2.8 \%$ milk fat $)$ and whole cow yogurt (3.0\% milk fat).Blood samples were obtained after at least $9 \mathrm{~h}$ of fasting in the early morning hours ( $8 \mathrm{am}-10$ $\mathrm{am})$ at the beginning and at the end of each intervention period. One stool sample and a 72-h dietary register were also collected at these time points. DIAL software was used to analyse the nutrients composition of volunteer's habitual diet, excluding the experimental products intake [21]. Plasma of the different patients was separated from blood samples, stored at $-80^{\circ} \mathrm{C}$, and used for the cortisol determination in all patients at the start and end of each intervention period.

\subsection{Extraction Procedure}

Four different fractions were separated in all the yogurts: total fraction (F1), peptidic (F2), phenolic (F3) and lipophilic (F4) fraction, in order to evaluate the contribution of each fraction in the total antioxidant activity. Total yogurt fraction (F1) was extracted using yogurt samples, which were centrifuged at $4,000 \times \mathrm{g}$ at $4^{\circ} \mathrm{C}$ for $30 \mathrm{~min}$ to homogenise sample. The sample obtained was freeze dried and stored at $-20^{\circ} \mathrm{C}$ for further analysis. Peptidic fraction (F2) was obtained according to [22]. Yogurt samples were centrifuged at 15,000 $\times \mathrm{g}$ at $4^{\circ} \mathrm{C}$ for $30 \mathrm{~min}$. The supernatant was filtered separately through a $0.45 \mu \mathrm{m}$ membrane filter and the filtrate was freeze dried and stored at $-20^{\circ} \mathrm{C}$ for further analysis. Phenolic fraction (F3) was obtained using $1 \mathrm{~g}$ of blended sample and dissolved in $10 \mathrm{Ml}(1: 1, \mathrm{v} / \mathrm{v}$; acidified to $\mathrm{pH}=2$ 
with $0.1 \mathrm{M} \mathrm{HCl}$ ) in a temperature-controlled orbital shaker $\left(25^{\circ} \mathrm{C}, 250 \mathrm{rpm}, 1 \mathrm{~h}\right)$. After centrifugation $\left(25^{\circ} \mathrm{C}, 3800 \mathrm{~g}, 10 \mathrm{~min}\right)$, the supernatant was collected, filtered and adjusted to $25 \mathrm{~mL}$ with the extracting solvent, and then, it was freeze-dried. Last fraction corresponded to lipophilic fraction (F4) that was obtained with methanol, and later with chloroform, and then the solution was filtered. The remaining residue was mixed with chloroform: methanol in a ratio $3: 1$ and $\mathrm{KCl} 0.88 \%$ was added. Organic layer was finally evaporated, freeze-dried and sample was stored at $-20^{\circ} \mathrm{C}$ for further analysis.

\subsection{Folin-Ciocalteu for Total Phenol (TPs) Assay}

The reducing capacity of yogurt fractions and the content in total phenols (TPs) was estimated using the Folin-Ciocalteu (FC) assay [23] following the procedure described in [24]. A calibration curve with gallic acid (GA) as standard (9.8-70 $\mu \mathrm{M}$ diluted in the extracting solvent) was used. Results were corrected for moisture and expressed as micrograms of Trolox equivalents per gram ( $\mu$ g Trolox Eq. /g).

\subsection{Total Antioxidant Activity (TAA) of Yogurts}

Classical methods for TAA were used to assess the potential antioxidant capacity of sample extracts and whole yogurt. DPPH (1,1-diphenyl-2-picrylhydrazyl) radical scavenging activity Radical (DPPH), Trolox Equivalent Antioxidant Capacity (TEAC) and Oxygen Radical Absorbance Capacity (ORAC) were evaluated. Relative antioxidant capacity (RACI) was also calculated.

\subsubsection{Oxygen Radical Absorbance Capacity (ORAC) Assay}

This method was based on a previously reported method [25] with slight modifications reported in [24]. Different concentrations of Trolox $(7.5-240 \mu \mathrm{M}$, diluted in the extracting solvent) were used to make the calibration curve. The results were calculated using the areas under the fluorescein decay curves between the blank (samples replaced by extracting solvent) and each sample. Final values were expressed as micromoles of Trolox equivalent per gram $(\mu \mathrm{molEq}$.Trolox $/ \mathrm{g})$.

\subsubsection{Trolox Equivalent Antioxidant Capacity (TEAC) Assays}

The classical version of this method was adapted from the assay developed by [26]. A stock ABTS+ solution was prepared by mixing a $7 \mathrm{mM}$ aqueous ABTS solution with $2.45 \mathrm{mM} \mathrm{K}_{2} \mathrm{O}_{8} \mathrm{~S}_{2}$ in a $1: 1(\mathrm{v} / \mathrm{v})$ ratio. Before the assay, the stock ABTS+ solution was diluted with phosphate buffer (75 mM, pH $=7.4$ ) to obtain a working solution with an absorbance value of $0.70 \pm 0.02$ at $734 \mathrm{~nm}$. A volume of $20 \mu \mathrm{L}$ of diluted samples was then mixed with $200 \mu \mathrm{L}$ ABTS+ working solution in a 96-well microplate. The decay in absorbance at $730 \mathrm{~nm}$ was monitored over 30 min with a microplate reader. The results were corrected for moisture and expressed micromols Trolox equivalents ( $\mu$ mol Trolox Eq./g).

\subsubsection{2,2-diphenyl-1-picrylhydrazyl(DPPH) Assays}

The classical version of this method is based on a previously reported assay [27] with slight modifications. A $100 \mu \mathrm{M}$ DPPH working solution in pure methanol was prepared. Afterwards, a volume of $25 \mu \mathrm{L}$ of extracts was mixed with $100 \mu \mathrm{L}$ of MilliQ water and $125 \mu \mathrm{L}$ of DPPH working solution in a 96-well microplate. The decay in absorbance at $515 \mathrm{~nm}$ was recorded over $30 \mathrm{~min}$ with a microplate reader. The results were expressed as percentage of inhibition ( $\%$ inhibition).

\subsubsection{RACI Index}

Relative antioxidant capacity index (RACI) is an integrated approach to evaluate the antioxidant capacity generated from different in vitro antioxidants parameters [28]. For the calculation, standard scores were used with no unit impediment and variance among them.

\subsection{Determination of Degree of Hydrolysis (DH)}

The degree of hydrolysis (DH) during fermentation of milk was quantified by determining free NH3 groups using the $o$-phthaldialdehyde method (OPA) with some modifications [22,29,30]. Protein content in water-soluble extracts were measured by Bradford method.

\subsection{Sodium Dodecyl Sulphate-Polyacrylamide Gel Electrophoresis (SDS-PAGE)}

SDS-PAGE analysis of yogurts was performed on $\mathrm{Nu}$ PAGE Novex 4-12\% Bis-Tris gels in the XCell-sure lock mini cell system (Invitrogen, Madrid, Spain). Electrophoresis was carried out at $200 \mathrm{~V}$. Nu PAGE MES-SDS and Nu PAGE LDS were used as running and sample buffers (Invitrogen), respectively. Runs were carried out under non-reducing conditions in which 2-mercaptoethanol was omitted in the denaturing buffer. Electrophoretic bands were stained with SimplyBlue Safe Stain (Invitrogen), followed by destaining in deionized water. The molecular weights of poly- and oligopeptides were determined by comparison with the molecular weight marker (Novex ${ }^{\circledR}$ Sharp Unstained Protein Standard, Invitrogen).

\subsection{High Performance Liquid Chromatography for Peptidic Analysis- HPLC-RP}

The water-soluble peptides in the traditional and commercialyogurts were profiled using a reverse-phase high performance liquid chromatography (RP-HLPC-Agilent)

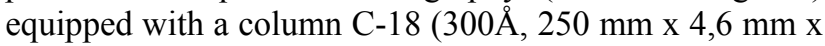
$5 \mu \mathrm{m})$ at $25^{\circ} \mathrm{C}$ according to the method used by [3]. The peptides were eluted in a linear gradient from $100 \%$ to $0 \%$ of solvent A $(0,1 \%$, v/v trifluoroacetic acid (TFA) in deionized water) in solvent $\mathrm{B}(0,1 \%$, v/v TFA in acetonitrile $)$ with a flow rate of $0,75 \mathrm{ml} / \mathrm{min}$ over $70 \mathrm{~min}$. All the samples were filtered through a $0.45 \mu \mathrm{m}$ filter and $20 \mu \mathrm{l}$ were injected. The eluted peptides were detected at $215 \mathrm{~nm}$ using a UV/Vis detector. 


\subsection{Cortisol determination}

Cortisol was determined in blood plasma using Enzyme-Linked Immuno Sorbent Assay (ELISA) (De Meditec, Germany). Plasma was used directly after dilution (1/300, with ELISA buffer. After centrifugation, the supernatant was diluted (1/5, with ELISA buffer) and used for the ELISA assay. According to manufacturer's instructions, preliminary tests were performed to assess for the necessity of purifying plasma before the ELISA assay. Linearity tests were performed with different dilutions of the samples. Calculated cortisol levels for the different dilutions differed less than a $20 \%$, and therefore, no extraction for the quantitative in vitro diagnostic measurement of cortisol in serum and plasma (EDTA) was performed. The microtiter wells were coated with an anti-cortisol antibody. An unknown amount of cortisol present in the sample competes with a cortisol-horseradish peroxidase conjugate for binding to the coated antibody. After incubation, the unbound conjugate is washed off. The amount of bound peroxidase conjugate is inversely proportional to the concentration of cortisol in the sample. After addition of the substrate solution, the intensity of colour developed is inversely proportional to the concentration of cortisol in the sample. The absorbance was measured at $450 \mathrm{~nm}$ and the cortisol was expressed in nanograms per $\mathrm{ml}(\mathrm{ng} / \mathrm{mL})$.

\subsection{Statistical Analysis}

Data were analysed by multifactor analysis of variance (multifactor ANOVA) of each independent variable. LSD test was applied for determining group differences at $95 \%$ of significance. Further multivariate analysis was performed using Principal Component Analysis (PCA). Statgraphics Centurion XVI was used for developing all statistical analysis.

\section{Results and Discussion}

\subsection{Antioxidant Total Activity}

Antioxidant activity was evaluated using different methods in set yogurt from different species' milk (cow, ewe), and with different fat content (whole and semi skimmed), in the different chemical compositional fractions (F1, F2, F3 and F4) and during all the experimental period (January to June) (Figure 1, Figure 2 and Figure 3).

Antioxidant activity was significantly $(p \leq 0.05)$ higher in $\mathrm{CW}$ than in ES and EW regardless of the assay utilised to measure the total antioxidant activity (Figure 1A). FRAP assay showed high significant differences $(p \leq 0.01)$ between species probably due to the antioxidants released during fermentation have a higher chelating ability in cow than in ewe, which might contribute to the high reducing activity. It has been reported that the activity Streptococcus thermophilus and other microorganisms such Lactobacillus acidophilus releases higher amount of chelators such as penincillamine during fermentation [31]. In addition, the process of fermentation generated higher breakdown of phenolic compounds by enzymatic activity of the starter culture in cow than ewe, probably associated to the fact that the commercial started proteolytic system acted more effectively in cow's protein linked to phenolics than in ewe's proteins [32].

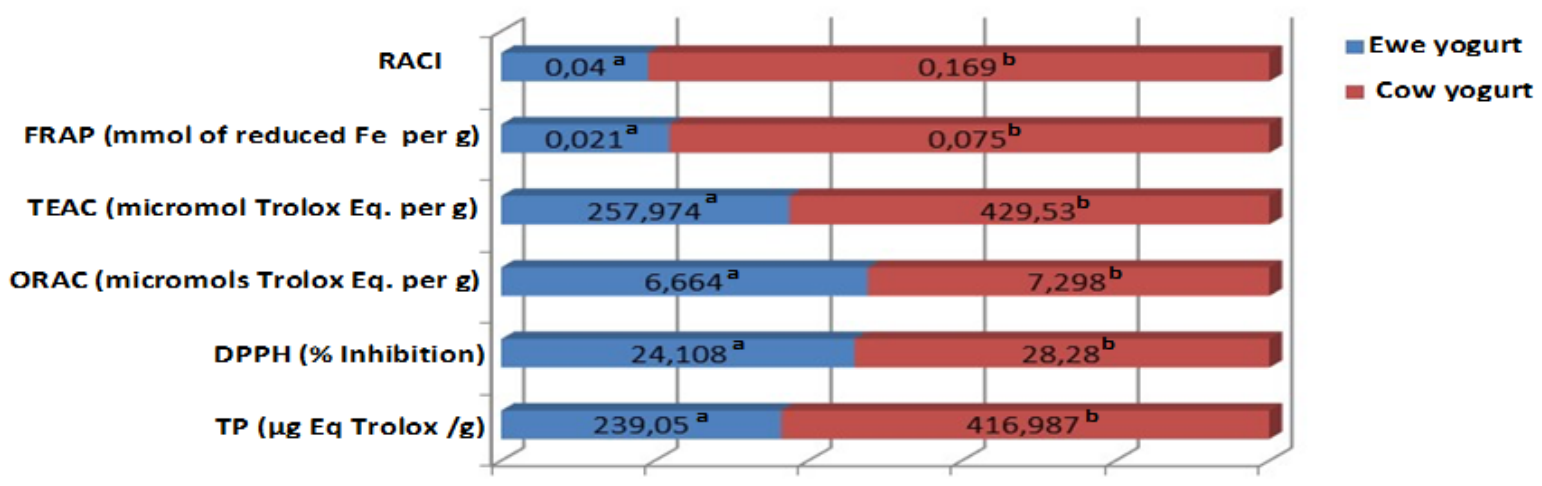

B)
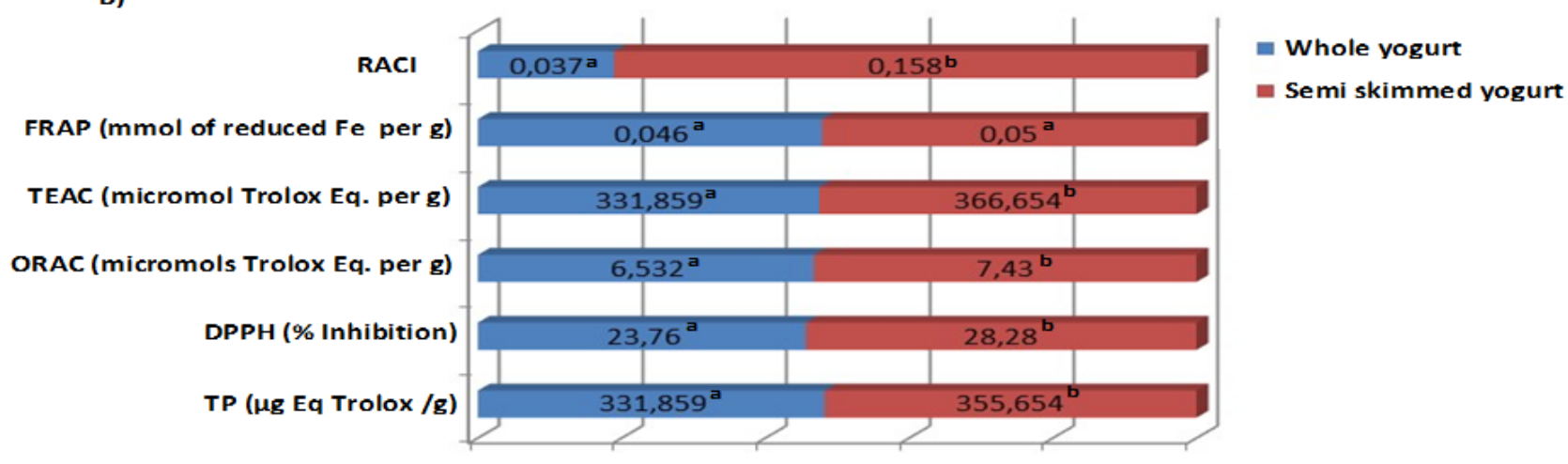

Figure 1.Total antioxidant activity (TAC) of yogurts for ewe versus cow yogurt (A) and semi skimmed versus whole yogurt (B). TAC assessed using TP, DPPH, ORAC, TEAC, FRAP and RACI. Significant differences $(\mathrm{p}<0.05)$ between samples are expressed in lower case Latin letters 
TEAC assay gave higher values of antioxidant activity than DPPH and ORAC methods for cow than for ewe yogurt. Maybe this can be associated to some milk components such as cysteine, glutathione, and protein sulfhydryls, which would be realised during fermentation of cow's milk in higher concentration and have higher ability to scavenge ABTS $\bullet+$ radicals $[33,34,35,36]$.

Fat content had a significant effect on the antioxidant activity, CW and ES yogurts presented higher antioxidant activity than EW yogurts (Figure 1B), although we expected higher values in yogurts prepared from milks with higher content in fat associated with the higher levels of antioxidants such as carotene. These results probably respond to other compounds different to lipids or antioxidant bounded lipids that exhibited higher contribution to the total antioxidant activity.

The different fractions obtained from yogurts showed different antioxidant activity (Figure 2A). Among them, peptidic fraction (F2) showed higher antioxidant activity than phenolic fraction (F3) and the total fraction (F1). These results can be attributed to the higher scavenging activity of proteins hydrolysed during fermentation that of free phenolics or lipidic fraction. An important number of studies indicate that the high antioxidant potential of milk is determined mainly by proteins $[37,38]$ and this is also demonstrated in yogurts. Both whey and casein proteins are highly active hydrophilic antioxidants present in yogurts [12].

The study of lipophilic fraction (F4) was evaluated using ORAC and TEAC and results showed also greater antioxidant activity of ewe than in cow F4 milk yogurts (Figure 2B), probably associated to the higher content on conjugated linoleic acid (CLA) in ewe versus cow according to previous results reported in previous studies by the authors $[12,20]$.

The batch also affected the antioxidant capacity of yogurts, mainly associated to the lactation period. Yogurts were produced in 12 batches along the time, from January to June (Figure 2C). Yogurts manufactured in the first months of the year showed less antioxidant activity than those manufactured from May to June. It has been associated to the modifications in animal feeding. Significant changes of bioactive compounds such as CLA and/or omega-3 fatty acids could be occur when the diet changes. [39] observe changes of $128 \%$ in summer and $0.54 \%$ in winter related with seasonal variations. These modifications could be also observed also in minerals content, although they are less related with antioxidant activity. During the months May to June, ewes grazed mainly on pastures, which leads to a higher increase of the antioxidant activity.

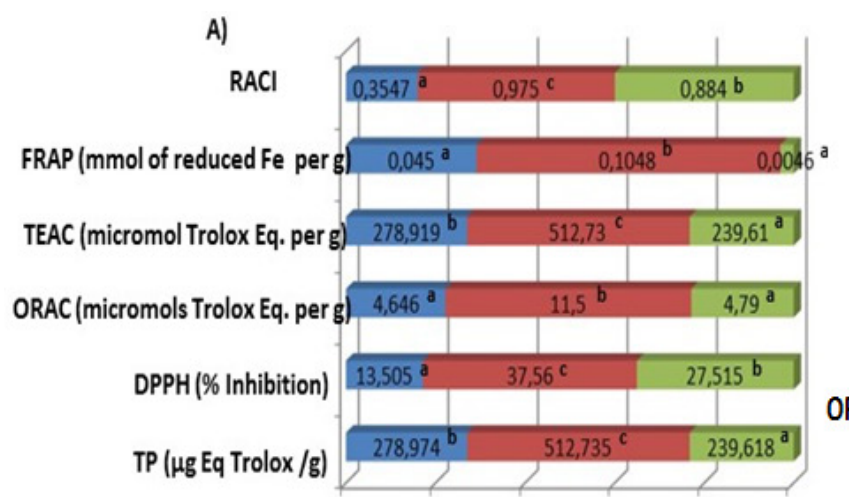

"TOTAL (F1)" PEPTIDIC(F2)" LIPIDIC(F3)

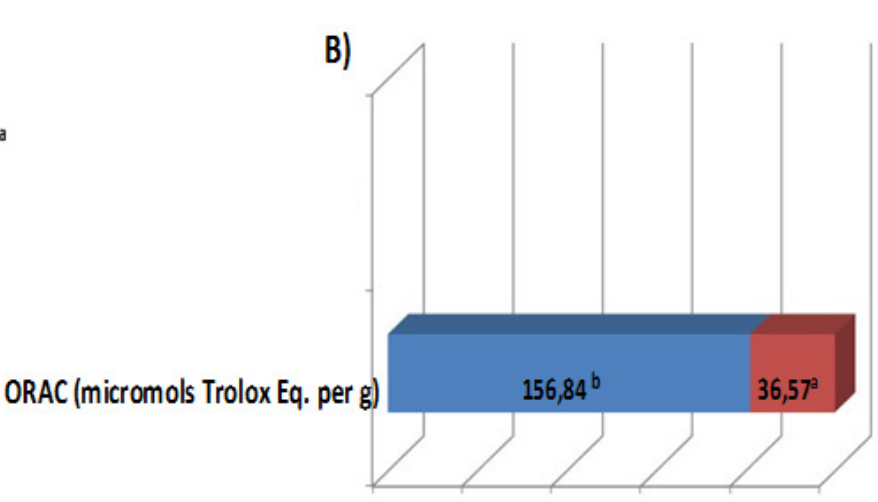

$\operatorname{COW}(\mathrm{F} 4) \quad \operatorname{EWE}(\mathrm{F} 4)$

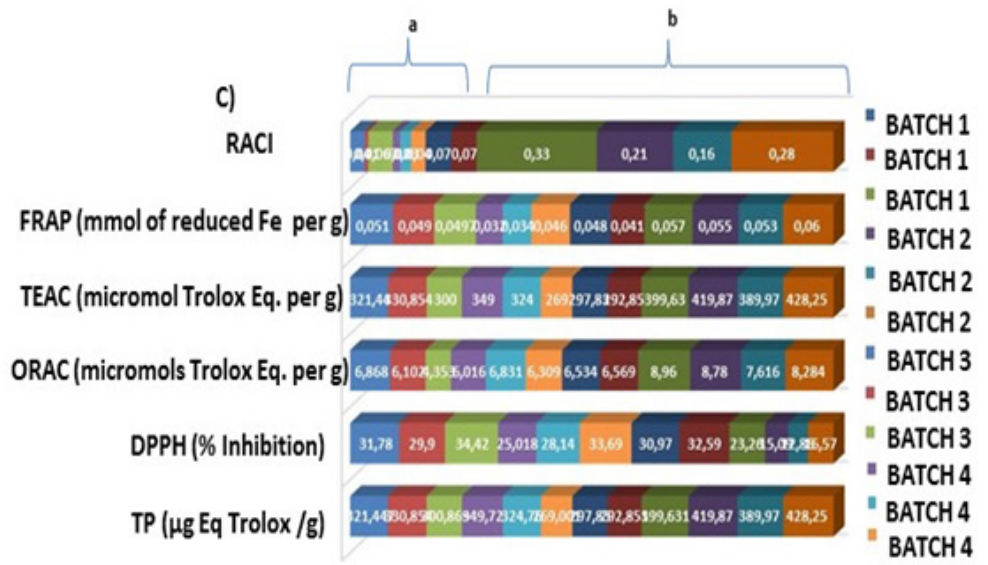

Figure 2. Total antioxidant activity (TAC) of yogurts for different fractions: total fraction (F1), peptidic (F2) fraction and lipidic fraction (F3) (A), ewe lipid fraction versus cow lipid fraction and total fraction for different batches (C). TAC assessed using TP, DPPH, ORAC, TEAC, FRAP and RACI. Significant differences $(p<0.05)$ between samples are expressed in lower case Latin letters 
A)

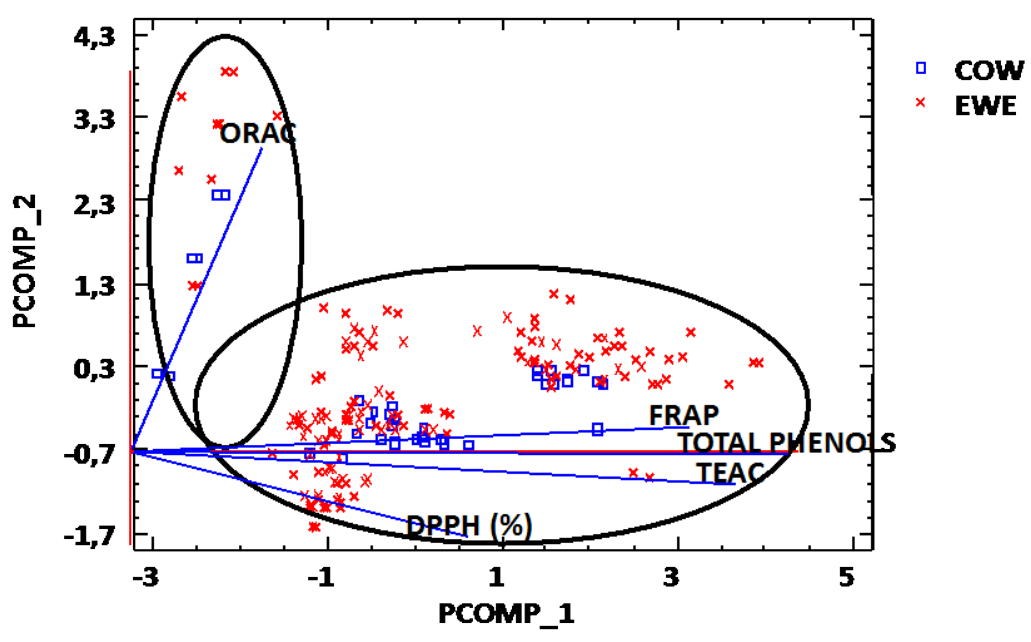

B)

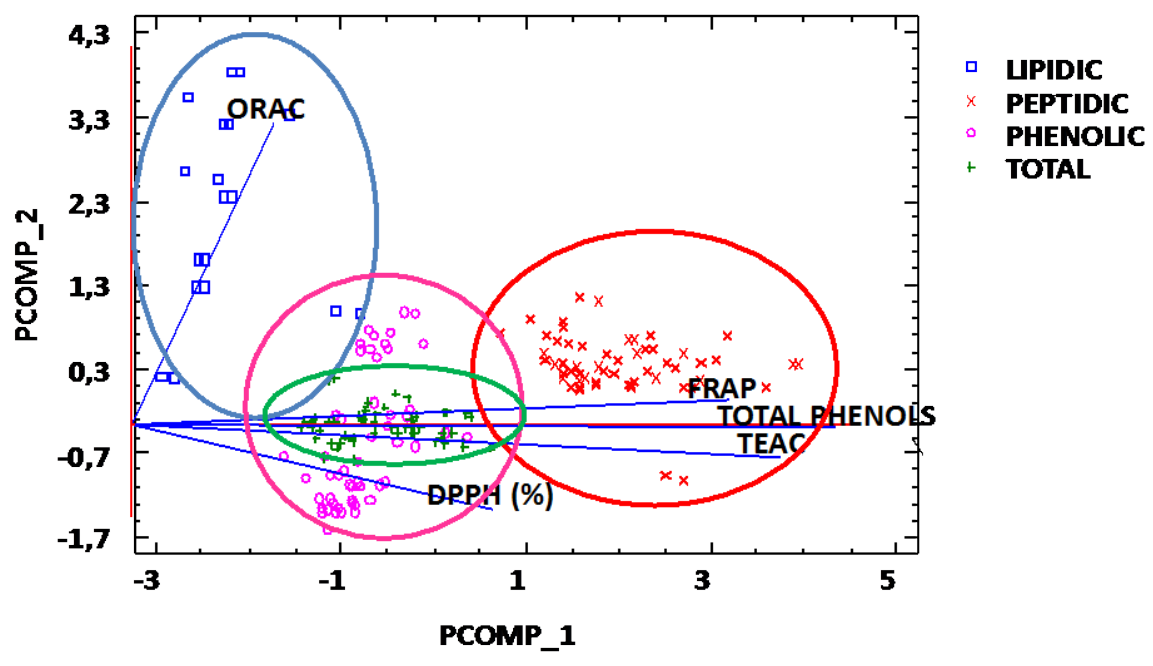

Figure 3. Principal Component Analysis (PCA) for TP, DPPH, ORAC, TEAC, FRAP and RACI for ewe and cow yogurts (A) and Principal Component Analysis (PCA) for TP, DPPH, ORAC, TEAC, FRAP and RACI for different yogurt fractions: total fraction (F1), peptidic fraction (F2), phenolic fraction (F3) and peptidic fraction (F4) (B)

Principal components analysis (Figure 3) showed significant distribution along the main components of all antioxidant markers studied. ORAC were separated from the other markers within differences between species (Figure 3A) The PC1 explained the $46.26 \%$ meanwhile the PC2 explained $66.41 \%$ of the variability. ORAC was associated mainly to lipidic fraction (F4) which has an important antioxidant activity meanwhile DPPH was associated with phenolic fraction (F3) and the peptidic fraction (F2). Since peptidic fraction showed higher antioxidant activity than the other fraction, further studies were conducted on this fraction.

\subsection{SDS-PAGE Protein Profile}

The electrophoretic patterns of the three types of yogurts produced in the present study are shown in Figure 4. As it can be observed, all cow's yogurts exhibited similar qualitative protein profile (Figure $4 \mathrm{~A}$ ), but slight quantitative differences in band intensity were observed depending of the period of time when the milk was obtained. The two major bands corresponded to $\beta$-lactoglobulin $(\sim 18 \mathrm{kDa})$ and $\alpha$-lactalbumin $(\sim 14 \mathrm{kDa})$ that did not show important qualitative differences in the yogurts produced from cow's milk obtained at different months. A band with an apparent molecular weight of $\sim 28$ $\mathrm{kDa}$ corresponding to caseins were also observed in all cow's yogurts, but the band intensity was slightly less intense in samples $\mathrm{CO} 7$ and CO9. Some bands with molecular weight lower than $10 \mathrm{kDa}$ were also detected in all cow's yogurt samples. These bands might correspond to oligopeptides released by cow's milk proteolysis by the starter culture used for yogurt production.

The protein pattern of yogurts produced from ewe's semi-skimmed (ES) milk and ewe's (Figure 4 B) was rather similar than that observed in cow's milk yogurts from a qualitative point of view, but quantitative differences were found. In this context, a lower intensity of the band corresponding to $\alpha$-lactalbumin was observed, as well as a more intense band of $\sim 28 \mathrm{kDa}$ that is in agreement with the higher concentration of $\beta$-casein fraction in ewe's milk than in cow's milk, as it has been previously reported [40,41]. In addition, an intense band with a molecular weight of $\sim 19 \mathrm{kDa}$ was visible, that probably correspond to $\kappa$-casein. The electrophoretic profile found in ewe's milk yogurt match with that 
previously reported [40]. Some bands with molecular weight lower than $15 \mathrm{kDa}$, corresponding to hydrolysis products of ewe's milk proteins as consequence of the proteolytic activity of the starter culture, were also observed in all ES yogurts. No significant differences in the protein pattern were observed between the different ES yogurts. The only exception was one band corresponding to one of the ewe's milk proteolytic products $(15 \mathrm{kDa})$ that was slightly lower in samples ES5, ES6 and ES7. As it was expected, ewe's whole (EW) milk yogurts (Figure $4 \mathrm{C}$ ) exhibited a similar electrophoretic pattern than ES yogurts, and no notable differences was observed between yogurts produced from EW milk obtained at different seasons.

A)

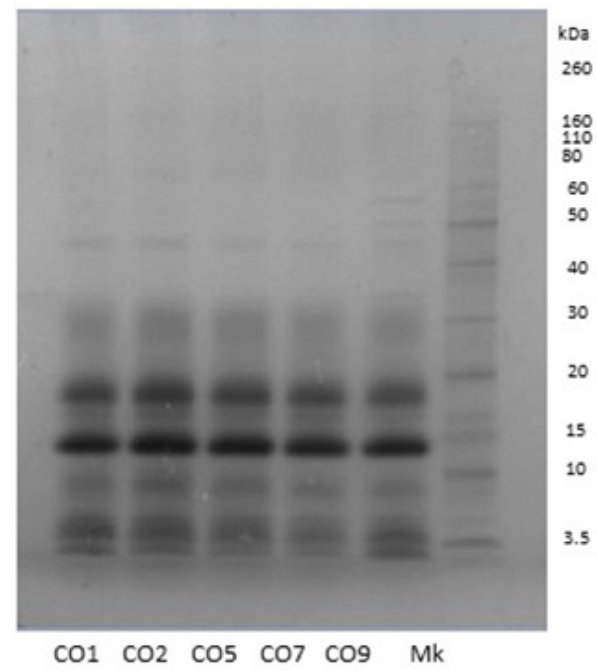

B)

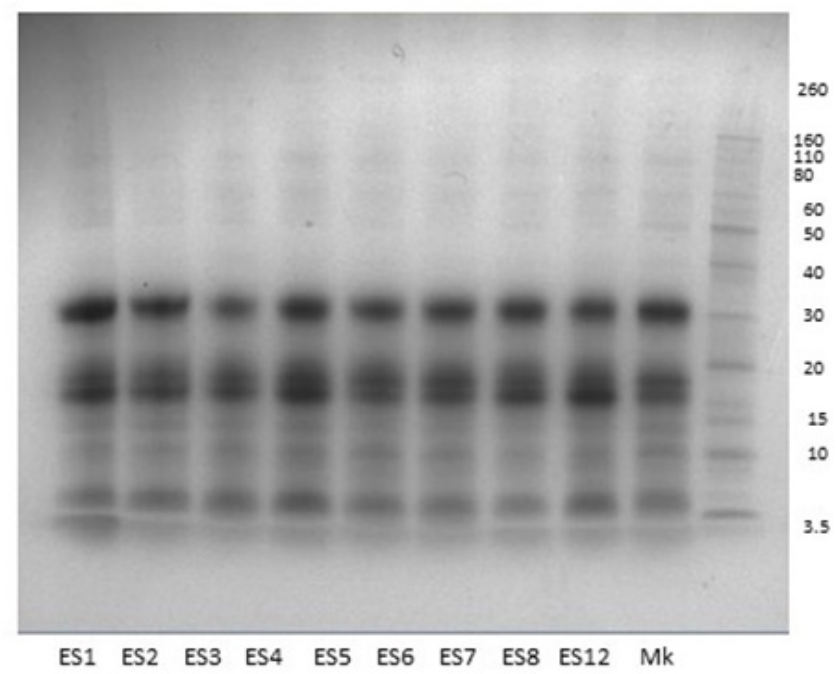

C)

\subsection{Determination of Degree of Hydrolysis (DH)}

The degree of protein hydrolysis in yogurts was determined by measuring the $\alpha$-amino groups released during milk fermentation using the o-phthaldialdehyde reaction (OPA). The result showed significant higher hydrolysis in ewe versus cow set yogurts (Table 1). However, this difference was not reflected in a higher antioxidant activity as it is expecting in the peptidic fraction. Probably although the hydrolysis was higher in ewe due to the hydrolytic activity of the starter culture during the fermentation the peptides produced had lower activity than those produced in cow.

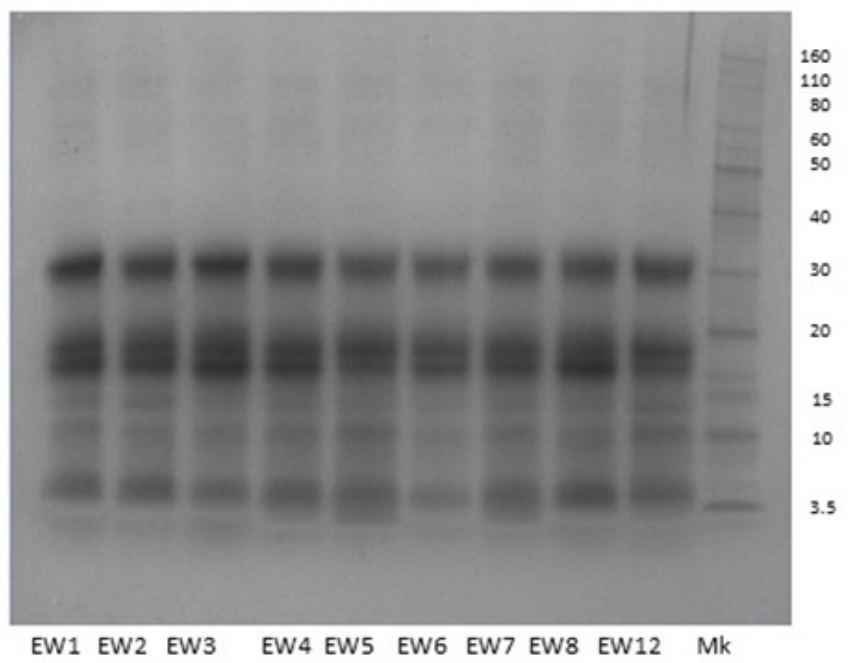

Figure 4. Dodecyl Sulfate-Polyacrylamide Gel Electroforesis (SDS-PAGE) for cow yogurt- CW (A), skimmed ewe yogurt-ES (B) and whole ewe yogurt-EW (C)

Table 1. Protein degree of hydrolysis of the peptidic fractions

\begin{tabular}{lcc}
\hline Yogurt & $\begin{array}{c}\text { \% Hydrophilic peptides } \\
(\text { mean } \pm \text { SD) }\end{array}$ & $\begin{array}{c}\text { \% Hydrophobic peptides } \\
(\text { mean } \pm \text { SD })\end{array}$ \\
\hline & & $36.86 \pm 17.15^{\mathrm{a}}$ \\
ES $(\mathrm{n}=12)$ & $63.14 \pm 17.15^{\mathrm{b}}$ & $44.61 \pm 19.13^{\mathrm{a}}$ \\
EW $(\mathrm{n}=12)$ & $54.39 \pm 19.13^{\mathrm{a}}$ & $66.75 \pm 15.74^{\mathrm{b}}$ \\
COW $(\mathrm{n}=5)$ & $33.25 \pm 15.74^{\mathrm{a}}$ & \\
\hline
\end{tabular}




\subsection{High Performance Liquid Chromatography for Peptidic Analysis}

Changes in peptide profiles during fermentation of different milks (cow and ewe-whole and semi skimmed) were analysed by RP-HPLC. Figure 5 shows the RPHPLC profiles obtained from different yogurts. Ewe's yogurt showed higher percentage in hydrophilic peptides than cow's yogurt, in which, the higher number of peptides produced during fermentation were hydrophobic. These differences were significantly higher in EW yogurt than in ES yogurt, where both fractions appeared equilibrated (Table 2). Cow's yogurt showed the presence of two peaks corresponding to the aglyco components of the two principal genetics variants (A and B) of caseinmacropeptides, which have been identified and reported as peptides released by the hydrolysis of kappacasein with high antioxidant activity [3]. The hydrophobic fraction usually presents higher antioxidant activity than hydrophilic amino acids [42] which explained the higher peptide ability to scavenge radicals observed in cow versus ewe peptidic fractions (Table 2, Figure 5).

Table 2. Percentage of hydrophilic and hydrophobic peptide fractions calculated using high performance liquid chromatography for peptidic analysis- HPLC-RP

\begin{tabular}{lc}
\hline Yogurt & $\begin{array}{c}\text { \% Protein Degree Hydrolysis } \\
(\text { mean } \pm \text { SD) }\end{array}$ \\
\hline & \\
Semi skimmed ewe yogurt $(\mathrm{n}=12)$ & $48.77 \pm 5.90^{\mathrm{a}}$ \\
Whole ewe yogurt $(\mathrm{n}=12)$ & $41.49 \pm 8.33^{\mathrm{a}}$ \\
Cow yogurt $(\mathrm{n}=12)$ & $36.12 \pm 2.78^{\mathrm{a}}$ \\
\hline
\end{tabular}

\subsection{Cortisol Determination}

Cortisol levels were measured on the plasma from 30 volunteers before and after the consumption of 3 types of yogurts. Baseline levels at the beginning of the consumption of each of yogurt ranged between 251 to $263 \mathrm{ng} / \mathrm{mL}$ as it shown in Table 3. The intake of yogurts, regardless of the type of specie (cow/ewe) and fat content (whole and semi skimmed), caused an increment on the final serum cortisol levels after 5 weeks of treatment.

The highest cortisol values were observed after the consumption of cow yogurts in all patients. Results showed only significant differences on final cortisol levels when the volunteers were divided by sex and CV risk (Figure 6). As it shown in Figure 6, significant difference ( $p=0.008$, post-hoc test with Bonferroni corrections) between the consumption of $\mathrm{CW}$ and $\mathrm{ES}$ yogurts were observed on women with low $\mathrm{CV}$ risk group. The study showed that women had a cortisol rate of change higher when they consumed cow yogurt, being lower the rate of change during ewe yogurt consumption and especially semi-skimmed yogurt (Figure 7). Since inflammatory process is in many cases related with high levels of cortisol [43], seems than SE yogurt seems to be a better alternative than cow yogurt concerning cortisol levels, although the results were only significant for woman with normal Cho-Index. In addition, the consumption of SE yogurt could contribute to the reduction of inflammatory processes and/or other metabolic disorders, decreasing the risk of suffering a chronic disease and improving state of health.

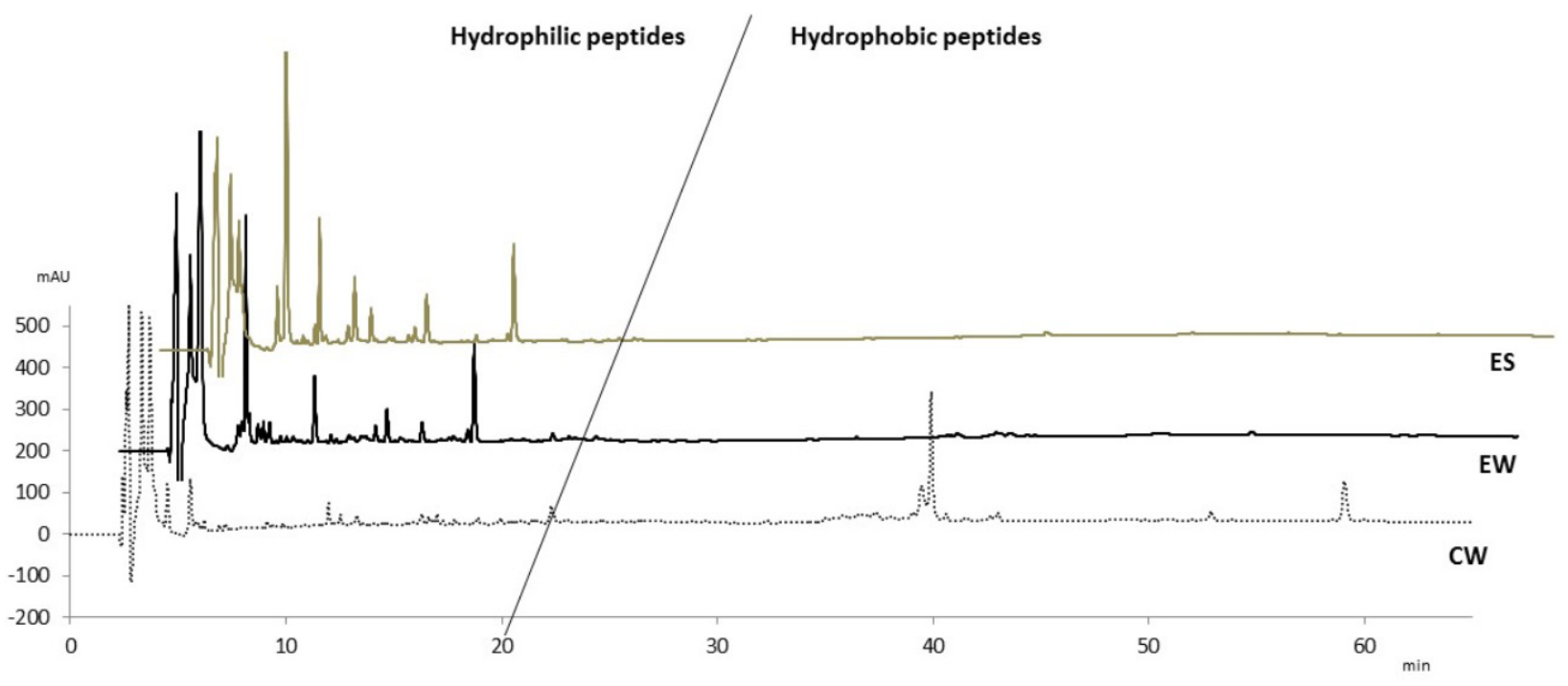

Figure 5. High performance liquid chromatography for peptidic analysis- HPLC-RP for peptidic yogurt fractions

Table 3. Cortisol levels of intervention study volunteers and rates of change [(Post-Tr/Pre-Tr)/Pre-Tr]

\begin{tabular}{|c|c|c|c|c|c|c|c|c|c|c|c|}
\hline \multirow[b]{2}{*}{ Mean (SD) } & \multicolumn{3}{|c|}{$\begin{array}{l}\text { Ewe semi-skimmed } \\
\operatorname{yogurt}(n=30)\end{array}$} & \multicolumn{3}{|c|}{$\begin{array}{l}\text { Ewe whole yogurt } \\
\qquad(\mathrm{n}=\mathbf{3 0})\end{array}$} & \multicolumn{3}{|c|}{$\begin{array}{c}\text { Cow yogurt } \\
(n=29)\end{array}$} & \multirow[b]{2}{*}{$\mathbf{P}^{\mathbf{a}}$} & \multirow[b]{2}{*}{$\mathbf{P}^{\mathbf{b}}$} \\
\hline & Pre-tr. & Post-tr. & $\begin{array}{l}\text { Rate of } \\
\text { change }\end{array}$ & Pre-tr. & Post-tr. & $\begin{array}{l}\text { Rate of } \\
\text { change }\end{array}$ & Pre-tr. & Post-tr. & $\begin{array}{l}\text { Rate of } \\
\text { change }\end{array}$ & & \\
\hline Cortisol (ng/mL) & $\begin{array}{l}261 \\
(64)\end{array}$ & $\begin{array}{l}266 \\
(74)\end{array}$ & $\begin{array}{c}0.03 \\
(0.27)\end{array}$ & $\begin{array}{l}251 \\
(67)\end{array}$ & $265(62)$ & $\begin{array}{c}0.10 \\
(0.32)\end{array}$ & $\begin{array}{l}263 \\
(66)\end{array}$ & $\begin{array}{l}289 \\
(53)\end{array}$ & $\begin{array}{c}0.18 \\
(0.49)\end{array}$ & 0.240 & 0.009 \\
\hline
\end{tabular}

${ }^{a}$ Treatment effect by lineal mixed models with treatment (Tr), CV risk (R) and sex (S) as fixed factors, visit as random factor, age as covariable and rates of change as dependent variables.

${ }^{\mathrm{b}}$ Interactions of treatment with other factors in the same lineal mixed model (interaction sex and CV risk with treatment). 

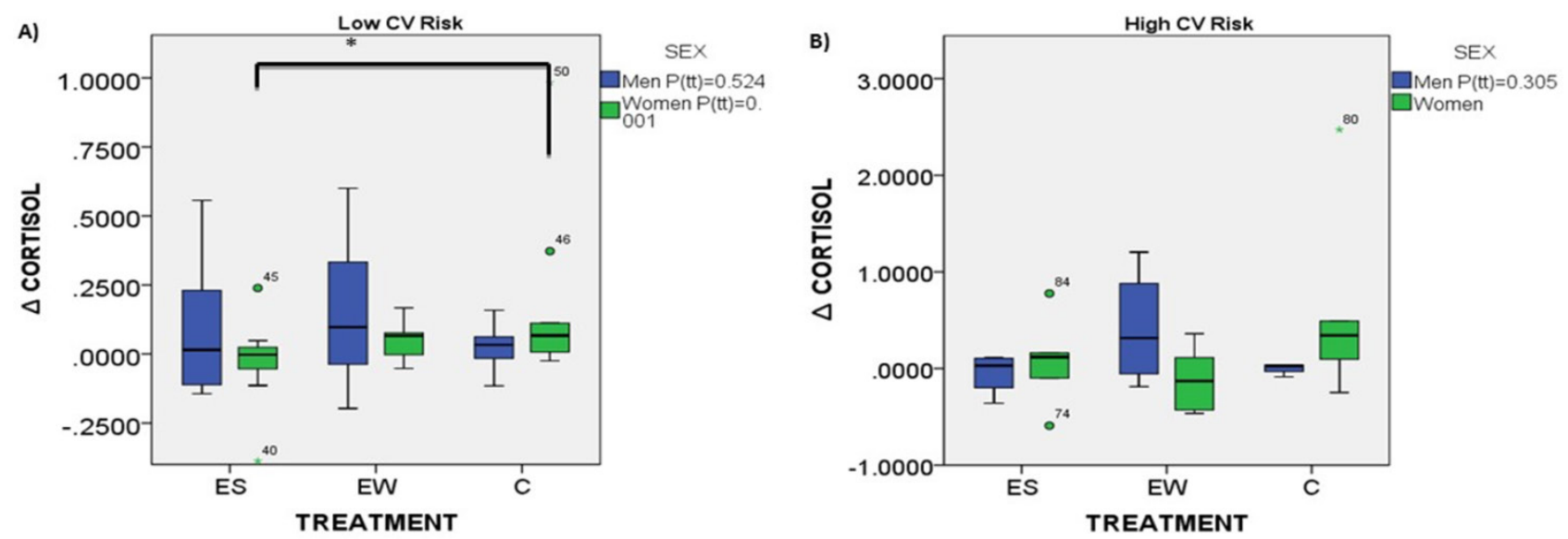

Treatment effect (Ptt) by lineal mixed models with treatment as fixed factor, visit as random factor, age as covariable and rates of change as dependent variables assessed in men (white boxes) and women (grey boxes) in both groups Low (A) (men N=10 and women $\mathrm{N}=10$ ) and High $\mathrm{CV}$ risk groups (B) (men $\mathrm{N}=4$ and women $\mathrm{N}=6$ ), separately. ${ }^{*}$ : $\mathrm{P}=0.008$ Significant differences between treatments by post-hoc test with Bonferroni correction

Figure 6. Cortisol changes after the consumption of three different types of yogurt (ES, ewe semi-skimmed yogurt; EW, ewe whole yogurt; C, cow yogurt)

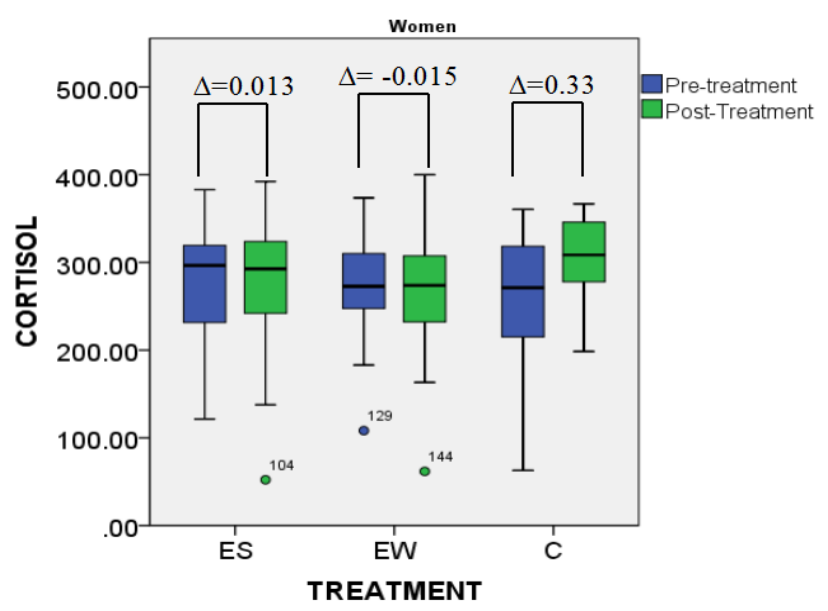

Figure 7. Cortisol levels before and after consumption of three different types of yogurt (ES, ewe semi-skimmed yogurt; EW, ewe whole yogurt; $\mathrm{C}$, cow yogurt) for women group $(\mathrm{N}=16)$

Other authors $[44,45]$ showed that the consumption of dairy products such as milk, cheese or yogurts, as part of diet, produce a significant decrease of cortisol levels. This fact was associated with the calcium [46] and $\alpha$ lactalbumin content $[47,48]$. Previous studies reported by [20] showed that ewe yogurt showed higher levels of calcium and protein than cow's yogurt which could be contribute to the results observed. It seems thatC increased cortisol levels compared to ewe yogurt (ES) in woman with normal cardiovascular risk. Many studies related CLA intake with a decrease of IgE, TNF- $\alpha$ and IL-1 $\beta$ $[47,49]$, however results previously published by the authors [21] showed that the consumption of ewe yogurt did not affect TNF- $\alpha$ differentially than cow yogurt consumption.

\section{Conclusion}

This study showed that cow yogurt has a higher total antioxidant activity than ewe yogurt. This capability might be associated to a higher peptidic fraction released during fermentation. However, lipidic fraction showed significant the higher CLA content. Cortisol levels were lower in normal risk women during ewe yogurt consumption, although no differences were observed in the males or women with higher cardiovascular risk, so it is difficult to conclude that cortisol levels were regulated or affected by the type of yogurt consumed.

\section{Acknowledgements}

This research was financed by MINECO Agro Technological Institute (ITACyL) and INIA (National Institute for Agricultural and Food Research and Technology)through the project RTA2012-00113-CO2-01 and co-financedthrough the European Regional Development Fund. Natalia García-González was the recipient of predoctoral contract FPI-INIA-19-2014, financed by INIA and the European Social Fund.

\section{Ethics Approval and Consent to Participate}

The current project was approved by the Hospital Universitario Puerta de Hierro-Majadahonda, (Madrid, Spain) (Record no 305, dated 9 December 2014) and the Bioethics Committee of the Spanish Scientific Research Council (CSIC). The study was carried out according to the Declaration of Helsinki (59 a General Assembly, Seúl, Corea, October 2008) and the Good Clinical Practices. Signed informed consent was obtained from all volunteers.

\section{Conflict of Interest}

There are no conflicts to declare.

\section{References}

[1] Bhat, Z.F. and H. Bhat, Milk and dairy products as functional foods: A review.Int J Dairy Sci, 2011. 6(1): p. 1-12. 
[2] Korhonen, H. and A. Pihlanto, Bioactive peptides: Production and functionality. Int Dairy J, 2006. 16(9): p. 945-960.

[3] Martin-Diana, A., M. Fraga, and J. Fontecha, Isolation and characterisation of caseinmacropeptide from bovine, ovine, and caprine cheese whey. Vol. 214. 2002. 282-286.

[4] Martín-Diana, A.B., et al., Development of a fermented goat's milk containing probiotic bacteria.Int Dairy J, 2003. 13(10): p. 827833.

[5] Niero, G., et al., <em $>$ Short communication: $</ e m>$ Selecting the most informative mid-infrared spectra wavenumbers to improve the accuracy of prediction models for detailed milk protein content.J Dairy Sci, 2015. 99(3): p. 1853-1858.

[6] Niero, G., et al., Effect of cheesemaking with microparticulated whey proteins on the concentration of low molecular thiols in cheese. Acta Agraria Kaposváriensis, 2014. 18: p. 103-108.

[7] Noziere, P., et al., Variations in carotenoids, fat-soluble micronutrients, and color in cows' plasma and milk following changes in forage and feeding level. J Dairy Sci, 2006. 89(7): p. $2634-48$.

[8] Jensen, S.K. and K.N. Nielsen, Tocopherols, retinol, betacarotene and fatty acids in fat globule membrane and fat globule core in cows' milk. J Dairy Res, 1996. 63(4): p. 565-74.

[9] Jelen, P., International Dairy Journal, 2005. 15(1): p. 93.

[10] Crumb, D. and D. Vattem, Conjugated linoleic acid (CLA)-An overview. Int J Appl Res Nat Prod, 2011. 4(3): p. 12-15.

[11] Singh, V. and N. Sachan, Nutraceutical properties of milk and milk products: A review. American Journal of Food Technology, 2011. 6(10): p. 864-869.

[12] Grażyna, C., et al., Natural antioxidants in milk and dairy products.Int J Dairy Tech, 2017.

[13] Elenkov, I.J. and G.P. Chrousos, Stress hormones, proinflammatory and antiinflammatory cytokines, and autoimmunity. Ann N Y Acad Sci, 2002. 966: p. 290-303.

[14] Walker, B.R., Glucocorticoids and cardiovascular disease.EurJ Endocrinol, 2007. 157(5): p. 545-559.

[15] Ferreira de Sá, D.S., et al., Cortisol, but not intranasal insulin, affects the central processing of visual food cues. Psychoneuroendocrinology, 2014. 50: p. 311-320.

[16] Brody, S., et al., A randomized controlled trial of high dose ascorbic acid for reduction of blood pressure, cortisol, and subjective responses to psychological stress. Psychopharmacology (Berl), 2002. 159(3): p. 319-24.

[17] Miklos, I.H. and K.J. Kovacs, GABAergic innervation of corticotropin-releasing hormone (CRH)-secreting parvocellular neurons and its plasticity as demonstrated by quantitative immunoelectron microscopy. Neuroscience, 2002. 113(3): p. 581-92.

[18] Starks, M.A., et al., The effects of phosphatidylserine on endocrine response to moderate intensity exercise.J Int Soc Sports Nutr, 2008. 5(1): p. 11

[19] Siepka, E., Ł. Bobak, and W. Gładkowski, Characteristics of the biological activity of egg yolk phospholipids. Żywn Nauk Technol Jakość, 2015. 2(99): p. 15-28.

[20] Olmedilla-Alonso, B., et al., Effect of ewe's (semi-skimmed and whole) and cow's milk yogurt consumption on the lipid profile of control subjects: a crossover study.Food Nutr Res, 2017. 61(1): p. 1391669.

[21] Redondo, N., et al., Effects of ewe's milk yogurt (whole and semiskimmed) and cow's milk yogurt on inflammation markers and gut microbiota of subjects with borderline-high plasma cholesterol levels: a crossover study. Eur J Nutr. 2018 Feb 16.

[22] Donkor, O.N., et al., ACE-inhibitory activity of probiotic yoghurt.Int Dairy J, 2007. 17(11): p. 1321-1331.

[23] Singleton, V.L. and J.A. Rossi, Colorimetry of total phenolics with phosphomolybdic-phosphotungstic acid reagents.Am J Enol Vitic, 1965. 16(3): p. 144-158.

[24] Martin-Diana, A.B., et al., Valorization of Carob's Germ and Seed Peel as Natural Antioxidant Ingredients in Gluten-Free Crackers.J Food Process Preserv, 2017. 41(2): p. e12770.

[25] Ou, B., M. Hampsch-Woodill, and R.L. Prior, Development and validation of an improved oxygen radical absorbance capacity assay using fluorescein as the fluorescent probe. J Agric Food Chem, 2001. 49(10): p. 4619-26.

[26] Re, R., et al., Antioxidant activity applying an improved ABTS radical cation decolorization assay. Free Radic Biol Med, 1999. 26(9-10): p. 1231-7.
[27] Brand-Williams, W., M.E. Cuvelier, and C. Berset, Use of a free radical method to evaluate antioxidant activity.LWT - Food Sci Tech, 1995. 28(1): p. 25-30.

[28] Sun, T. and S. Tanumihardjo, An integrated approach to evaluate food antioxidant capacity.J Food Sci, 2007. 72(9).

[29] Church, F.C., et al., Spectrophotometric Assay Using $<e m>0</ e m>$-Phthaldialdehyde for Determination of Proteolysis in Milk and Isolated Milk Proteins $<$ sup $>1</$ sup $>$.J Dairy Sci, 1983. 66(6): p. 1219-1227.

[30] Nielsen, P.M., D. Petersen, and C. Dambmann, Improved Method for Determining Food Protein Degree of Hydrolysis.J Food Sci, 2001. 66(5): p. 642-646.

[31] Lin, M.-Y. and C.-L. Yen, Antioxidative ability of lactic acid bacteria.J Agric Food Chem, 1999. 47(4): p. 1460-1466.

[32] Sabokbar, N., F. Khodaiyan, and M. Moosavi-Nasab, Optimization of processing conditions to improve antioxidant activities of apple juice and whey based novel beverage fermented by kefir grains.J Food Sci Tech, 2015. 52(6): p. 3422-3432.

[33] Rival, S.G., C.G. Boeriu, and H.J. Wichers, Caseins and casein hydrolysates. 2. Antioxidative properties and relevance to lipoxygenase inhibition.J Agri Food Chem, 2001. 49(1): p. 295302.

[34] Cao, G. and R.L. Prior, Comparison of different analytical methods for assessing total antioxidant capacity of human serum.Clin Chem, 1998. 44(6): p. 1309-1315.

[35] Suetsuna, K., H. Ukeda, and H. Ochi, Isolation and characterization of free radical scavenging activities peptides derived from casein.J Nutr Biochem, 2000. 11(3): p. 128-131.

[36] Chen, J., et al., Antioxidant capacity of bovine milk as assayed by spectrophotometric and amperometric methods.Int Dairy J, 2003. 13(12): p. 927-935.

[37] Zulueta, A., et al., Antioxidant capacity of cow milk, whey and deproteinized milk.Int Dairy J, 2009. 19(6-7): p. 380-385.

[38] Mann, B., et al., Antioxidant activity of whey protein hydrolysates in milk beverage system.J Food Sci Technol, 2015. 52(6): p. 32353241.

[39] Chilliard, Y. and A. Ferlay, Dietary lipids and forages interactions on cow and goat milk fatty acid composition and sensory properties.Reprod Nutr Dev, 2004. 44(5): p. 467-492.

[40] Yuksel, Z., et al., General composition and protein surface hydrophobicity of goat, sheep and cow milk in the region of Mount Ida.Small Rumin Res, 2012. 106(2): p. 137-144.

[41] Restani, P., et al., Cross-reactivity between milk proteins from different animal species. Clin Exp Allergy, 1999. 29(7): p. 9971004.

[42] Saidi, S., et al., Antioxidant properties of peptide fractions from tuna dark muscle protein by-product hydrolysate produced by membrane fractionation process. Food ResInt, 2014. 65: p. 329336.

[43] Connell, J.M., et al., Effects of ACTH and cortisol administration on blood pressure, electrolyte metabolism, atrial natriuretic peptide and renal function in normal man. J Hypertens, 1987. 5(4) p. 425-33.

[44] Witbracht, M.G., et al., Dairy Food Consumption and MealInduced Cortisol Response Interacted to Influence Weight Loss in Overweight Women Undergoing a 12-Week, Meal-Controlled, Weight Loss Intervention.J Nutr, 2013. 143(1): p. 46-52.

[45] Morris, K.L. and M.B. Zemel, 1,25-dihydroxyvitamin D3 modulation of adipocyte glucocorticoid function. Obes Res, 2005. 13(4): p. 670-7.

[46] Markus, C.R., B. Olivier, and E.H. de Haan, Whey protein rich in alpha-lactalbumin increases the ratio of plasma tryptophan to the sum of the other large neutral amino acids and improves cognitive performance in stress-vulnerable subjects. Am J Clin Nutr, 2002. 75(6): p. 1051-6.

[47] Benjamin, S., et al., Pros and cons of CLA consumption: an insight from clinical evidences. Nutr Metab (Lond), 2015. 12: p. 4.

[48] Markus, C.R., et al., The bovine protein alpha-lactalbumin increases the plasma ratio of tryptophan to the other large neutral amino acids, and in vulnerable subjects raises brain serotonin activity, reduces cortisol concentration, and improves mood under stress. Am J Clin Nutr, 2000. 71(6): p. 1536-44.

[49] Song, H.J., et al., Effect of CLA supplementation on immune function in young healthy volunteers.Eur J Clin Nutr, 2005. 59(4): p. 508-17. 